\title{
pH e Amônia Ruminais, Relação Folhas:Hastes e Degradabilidade Ruminal da Fibra de Forrageiras Tropicais ${ }^{1}$
}

\author{
Cristina Mattos Veloso², Norberto Mário Rodriguez ${ }^{3}$, Ivan Barbosa Machado Sampaio ${ }^{3}$, Lúcio \\ Carlos Gonçalves ${ }^{3}$, Gerson Barreto Mourão ${ }^{4}$
}

\begin{abstract}
RESUMO - Este experimento foi realizado com o objetivo de avaliar o pH e a concentração de nitrogênio amoniacal $\left(\mathrm{N}^{\left.-\mathrm{NH}_{3}\right)}\right.$ do líquido ruminal coletado 3, 6 e 12 horas após a alimentação de quatro novilhos mestiços Europeu-Zebu, providos de cânulas ruminais permanentes, assim como a relação folhas:hastes e as degradações ruminais in situ da fibra em detergente neutro (FDN) e da fibra em detergente ácido dos folíolos de três leguminosas tropicais: leucena (Leucaena leucocephala (Lam.) de Wit), guandu (Cajanus cajan (L.) Millsp.) e soja perene (Neonotonia wightii) e das folhas de outras duas forrageiras tropicais: rami (Boehmeria nivea (L.) Gaudich) e mandioca (Manihot esculenta Crantz). Amostras de $3 \mathrm{~g}$ de guandu, soja e rami ou $5 \mathrm{~g}$ de leucena e mandioca foram incubadas no rúmen dos animais por períodos de 3, 6, 12, 18, 24 e 48 horas. O delineamento experimental utilizado foi o de parcelas subdivididas, em que as parcelas eram representadas pelas forrageiras e as subparcelas, pelos seis horários de incubação do material no rúmen, sendo os quatro animais considerados blocos. Os valores de $\mathrm{pH}$ e N-NH 3 no rúmen provavelmente permitiram adequada fermentação microbiana. As relações folhas:hastes das forrageiras variaram entre si e em relação à literatura. As degradabilidades efetivas (DE) da FDN das forrageiras avaliadas foram em torno de $50 \%$, sendo menores para os folíolos de guandu (19,25\%), que também demonstraram as menores taxa de degradação $(2,5 \% / \mathrm{h})$ e degradabilidade potencial (57,76\%). Os valores de DE da FDN foram negativamente correlacionados aos conteúdos de nitrogênio insolúvel em detergente ácido das forragens $(r=-0,986)$. O guandu foi a pior forrageira quanto ao aproveitamento dos componentes estruturais.
\end{abstract}

Palavras-chave: desaparecimento ruminal da fibra, forragens tropicais, novilhos, rúmen

\section{Ruminal pH and Ammonia, Tropical Forage Leaves: Stems Ratio and Fiber Ruminal Degradability}

\begin{abstract}
The experiment was conducted to evaluate the ruminal $\mathrm{pH}$ and ammonia concentration $\left(\mathrm{N}-\mathrm{NH}_{3}\right)$ in rumen liquor collected at 3, 6 and 12 hours after feeding using four ruminal fistulated European x Zebu steers. The forage leaves: stems ratio and neutral detergent fiber (NDF) and acid detergent fiber in situ ruminal degradability of the leaflets from three tropical legumes (leucaena, Leucaena leucocephala; pigeon pea, Cajanus cajan; and glycine, Neonotonia wightii) and leaves from two others tropical forages (ramie, Boehmeria nivea and cassava, Manihot esculenta) were also studied. Samples of $3 \mathrm{~g}$ (pigeon pea, glycine and ramie) or $5 \mathrm{~g}$ (leucaena and cassava) of the material were incubated in the rumen of the animals for periods of 3, 6, 12, 18, 24 and 48 hours. A split-plot design was used, in which plots were the forages and split plots were the six periods of ruminal incubation of the material, and the four animals were considered blocks. Ruminal $\mathrm{pH}$ and $\mathrm{N}-\mathrm{NH}_{3}$ values probably allowed an adequate microbial fermentation. Forage leaves:stems ratio was variable among them and comparing to the literature. The forages NDF effective degradabilities (ED) were around 50\%, being lower for pigeon pea leaflets (19.25\%), which also demonstrated the lowest degradation rate $(2.5 \% / \mathrm{h})$ and potential degradability $(57.76 \%)$. ED values for NDF were negatively correlated to forages acid detergent insoluble nitrogen contents $(r=-0.986)$. Pigeon pea was the worst forage concerning to the use of structural components.
\end{abstract}

Key Words: fiber ruminal disappearance, tropical forages, steers, rumen

\section{Introdução}

O aumento da produtividade animal está diretamente relacionado à qualidade da alimentação fornecida aos animais. O alimento de escolha para ruminantes são as forragens, as quais, além de ter menor custo que os concentrados, não causam competição entre estes e os monogástricos. No entanto, a estacionalidade da oferta de alimentos (escassez nos meses mais frios e secos do ano e fartura na época de chuvas), assim como as baixas produção e qualidade das pastagens, prejudica a exploração pecuária no Brasil.

\footnotetext{
${ }^{1}$ Parte da Dissertação de Mestrado do primeiro autor apresentada ao DZO da EV/UFMG. Bolsista da CAPES.

${ }^{2}$ MSc em Zootecnia, Professora do Departamento de Tecnologia Rural e Animal da UESB. Pç. Primavera, 40 - CEP 45.700-000 - Itapetinga - BA. Aluna do Curso de Doutorado em Zootecnia - Departamento de Zootecnia da UFV. E.mail: cmveloso@uesb.br

${ }^{3}$ Professor do Departamento de Zootecnia da Escola de Veterinária da UFMG. Pesquisador do CNPq. E.mail: norberto@vet.ufmg.br; ivan@vet.ufmg.br; luciocg@vet.ufmg.br

${ }^{4}$ MSc em Zootecnia, Professor das Faculdades de Medicina Veterinária da UMESP e da FESB. E.mail: mouraogb@hotmail.com
} 
Como forma de avaliação de alimentos para ruminantes, a técnica do saco de náilon suspenso no rúmen para estimar a degradabilidade de determinado alimento, por intermédio do desaparecimento do mesmo após diferentes tempos de incubação no rúmen, tem-se apresentado como alternativa viável, principalmente em função de sua simplicidade e economicidade (ØRSKOV e McDONALD, 1979).

Os estudos de degradação ruminal de forrageiras tropicais conduzidos no Brasil fornecem dados que contribuem para a confecção de uma tabela nacional de composição de alimentos tropicais.

O objetivo deste trabalho foi estudar o $\mathrm{pH}$ e a concentração de nitrogênio amoniacal ruminais, a relação folhas:hastes e a degradabilidade, no rúmen, da fibra em detergente neutro e da fibra em detergente ácido de forrageiras tropicais utilizadas ou com potencial de utilização na alimentação de ruminantes.

\section{Material e Métodos}

Foram utilizados quatro novilhos mestiços europeuzebu, com idade média de 24 meses e peso vivo médio inicial de $320 \mathrm{~kg}$. Todos os animais foram fistulados e providos de cânulas ruminais permanentes.

Os animais foram alimentados com uma dieta básica, sendo $60 \%$ da matéria seca (MS) de feno de capimbraquiária (Brachiaria decumbens Stapf) picado a 1,5 cm e $40 \%$ de concentrado, composto por $45 \%$ de milho desintegrado e $55 \%$ de farelo de algodão.

As rações foram formuladas considerando-se um consumo de MS de aproximadamente $2,0 \%$ do peso vivo. A dieta foi oferecida em duas refeições diárias, divididas em partes iguais, às 7 e $19 \mathrm{~h}$, juntamente com o fornecimento de mistura mineral completa correspondente a cerca de $1,0 \%$ do peso da refeição.

Os sacos utilizados foram confeccionados em náilon com poros de $50 \mu \mathrm{m}$ de diâmetro, nas dimensões de 8 x $15 \mathrm{~cm}$, selados, nas bordas, por fusão em chama, pressionando-as entre duas placas de metal, devidamente identificados e, posteriormente, secos a $65^{\circ} \mathrm{C}$ por 24 horas e registrados seus pesos. Posteriormente, foram enchidos com $3 \mathrm{~g}$ (guandu, soja e rami) ou $5 \mathrm{~g}$ (leucena e folhas de mandioca) da forrageira a ser estudada, previamente moída em peneira de malha de $2 \mathrm{~mm}$, resultando em uma relação de $11 \mathrm{mg}$ de $\mathrm{MS} / \mathrm{cm}^{2}$ de área dos sacos de náilon para guandu, soja e rami e de $18 \mathrm{mg} / \mathrm{cm}^{2}$ para leucena e folhas de mandioca.

Após o enchimento, cada saco teve sua extremidade aberta dobrada e foi preso a uma argola de plástico (de 2,5 cm de diâmetro) e atado firmemente por intermédio de uma borracha elástica. Os sacos foram presos, por meio das argolas, a um aro de contenção que mantinha três argolas e, conseqüentemente, três sacos. Quatro aros estavam ligados, por cordões de náilon (de $4 \mathrm{~mm}$ de diâmetro e $40 \mathrm{~cm}$ de comprimento), a um cilindro de metal de $350 \mathrm{~g}$ de peso $(\operatorname{com} 8 \times 3 \mathrm{~cm})$ - funcionando como âncora -, no qual ambas as extremidades eram providas de alças próprias para fixação de cordões. Dessa forma, foram incubados 12 sacos por animal. O quinto cordão de náilon, que ligava uma das extremidades da âncora até o exterior do animal, tinha $50 \mathrm{~cm}$.

Após presos à âncora, os sacos contendo o material foram embebidos em água e, em seguida, introduzidos no rúmen, via cânula, sempre antes da refeição matinal, às $7 \mathrm{~h}$, exceto para o horário de incubação de 18 horas, para o qual a colocação dos sacos no rúmen foi feita às $19 \mathrm{~h}$, antes da segunda refeição diária. Os tempos de incubação utilizados foram 3, 6, 12, 18, 24 e 48 horas.

Retirados do rúmen, os sacos foram imediatamente imersos em água fria e posteriormente lavados, manualmente, em água corrente até que esta escorresse límpida. O elástico e a argola foram retirados e os sacos, acondicionados em bandejas de alumínio e colocados para secar em estufa de ventilação forçada de ar a $65^{\circ} \mathrm{C}$, onde permaneceram por 48 horas, sendo, então, transferidos para dessecador durante 30 minutos e pesados, descontando-se o peso dos sacos vazios e limpos, para determinação do desaparecimento de matéria seca no rúmen.

Para cada forrageira, três sacos foram mantidos como controle para fornecerem a estimativa do tempo de colonização. O procedimento para esta determinação consistiu em colocar, nos sacos de náilon, a mesma quantidade de amostra utilizada para os demais horários de incubação, fechá-los e lavá-los em água por vinte minutos, sem apertá-los, determinando, assim, a fração solúvel de cada alimento.

De cada alimento, dos resíduos após incubação das forrageiras no rúmen dos bovinos e do controle, foram retiradas amostras, que foram moídas em moinho com peneira de $1 \mathrm{~mm}$ e acondicionadas em vidros hermeticamente fechados e identificados para que fossem, posteriormente, analisadas para os seguintes parâmetros: $\mathrm{MS}$ em estufas a $65^{\circ} \mathrm{C}$, por 48 horas, e a $105^{\circ} \mathrm{C}$, por 6 horas, e fibra em detergente neutro (FDN), fibra em detergente ácido (FDA) e, no caso dos alimentos, também o nitrogênio insolúvel em detergente ácido (NIDA), pelo método seqüencial de 
ROBERTSON e VAN SOEST (1981).

Os teores de carboidratos não-estruturais (CNE) das forrageiras foram calculados utilizando-se a fórmula: $\% \mathrm{CNE}=100-[(\% \mathrm{FDN}-\mathrm{NIDA})+\% \mathrm{~PB}+\% \mathrm{EE}+\%$ Cinzas $]$, em que $\mathrm{PB}$ é a proteína bruta e EE, o extrato etéreo (COOMER et al., 1993).

Foram coletadas alíquotas de líquido ruminal dos quatro animais para determinação de $\mathrm{pH}$ e concentração de nitrogênio amoniacal $\left(\mathrm{N}-\mathrm{NH}_{3}\right)$ nos horários de 3, 6 e 12 horas após o fornecimento da refeição matinal. $\mathrm{O} \mathrm{pH}$ foi determinado em potenciômetro modelo Beckman Expandomatic S-2 e o N-NH dosado por destilação em óxido de magnésio e cloreto de cálcio, utilizando-se ácido bórico como solução receptora e ácido clorídrico $0,01 \mathrm{~N}$ para titulação (ASSOCIATION OF OFFICIAL ANALYTICAL CHEMISTS - AOAC, 1980).

O delineamento experimental utilizado foi o de parcelas subdivididas, em que os quatro animais representaram os blocos; as cinco forragens, os tratamentos; e os seis horários de incubação dos alimentos no rúmen, os subtratamentos.

As equações de regressão utilizadas para estimar a degradabilidade da matéria seca, da fibra em detergente neutro e da fibra em detergente ácido das forrageiras, em determinado tempo de incubação, foram não-lineares do tipo:

$$
\mathrm{Dg}=\mathrm{A}-\mathrm{B} \cdot \mathrm{e}^{\mathrm{ct}}
$$

em que

$D g$ é a porcentagem de degradação após um tempo $\mathrm{t} ; A$, a porcentagem máxima de degradação do material contido no saco de náilon; $B$, um parâmetro sem valor biológico de interesse. Se não houvesse tempo de colonização, ele corresponderia ao total a ser degradado pela ação de microrganismos; $c$ é a taxa constante de degradação da fração que permanece no saco de náilon (B); e $t$, o tempo de incubação no rúmen.

Após a estimativa dos parâmetros $A, B$ e $c$, os tempos de colonização (TC, em horas) dos alimentos estudados foram calculados de acordo com a seguinte equação, proposta por McDONALD (1981):

$$
\mathrm{TC}=-\frac{1}{\mathrm{c}} \cdot \ln \frac{(\mathrm{A}-\mathrm{S})}{\mathrm{B}}
$$

em que

$A, B$ e $c$ são os mesmos parâmetros definidos na equação (1); e

$S$ é a fração prontamente solúvel, determinada pela porcentagem de desaparecimento no tempo zero de incubação.

As degradabilidades efetivas (DE) foram calculadas considerando-se a taxa de passagem do rúmen (k), utilizando o valor sugerido pelo AGRICULTURAL RESEARCH COUNCIL - ARC (1984), de 5\%/hora, para nível médio de consumo, segundo modelo proposto por ØRSKOV e MCDONALD (1979):

$$
\mathrm{DE}=\mathrm{S}+\frac{\mathrm{B}_{1} \cdot \mathrm{c}}{\mathrm{c}+\mathrm{k}}
$$

em que

$S$ e $c$ são os mesmos parâmetros definidos nas equações (1) e (2); $B_{1}$ é a fração degradável, calculada subtraindo-se do potencial de degradação $A$, a fração solúvel $(S)\left(\mathrm{B}_{1}=\mathrm{A}-\mathrm{S}\right)$; e $k$ é a taxa estimada de passagem dos sólidos no rúmen.

\section{Resultados e Discussão}

Os valores mínimo e máximo de $\mathrm{pH}$, de 6,60 e 7,21 , encontram-se dentro da faixa de valores citada por ØRSKOV (1994), indicando serem compatíveis com atividades celulolítica e proteolítica normais, não tendo afetado, provavelmente, a fermentação ruminal.

A concentração média de nitrogênio amoniacal $\left(\mathrm{N}-\mathrm{NH}_{3}\right)$ no líquido ruminal coletado 3, 6 e 12 horas após o fornecimento da refeição matinal foi de $26,06 \mathrm{mg} / 100 \mathrm{~mL}$ e o pH médio, de 6,83. O nível médio de $\mathrm{N}-\mathrm{NH}_{3}$ observado foi bastante superior a $5 \mathrm{mg} / 100 \mathrm{~mL}$ e a $10 \mathrm{mg} / 100 \mathrm{~mL}$, que, segundo SATTER e SLYTER (1974) e VAN SOEST (1994), seriam, respectivamente, as concentrações mínimas necessárias para permitir adequada fermentação microbiana no rúmen. Foi também superior aos $23 \mathrm{mg} / 100 \mathrm{~mL}$ observados por MEHREZ e ØRSKOV (1977), quando obtiveram o maior desaparecimento da MS.

A relação folhas:hastes verificada para a leucena, 2,7:1 (Tabela 1), foi inferior às encontradas por Mendoza e Javier (1982), citados por SAAVEDRA VELEZ (1986), de 3,44:1, e JONES et al. (1992), de 3,42:1. No entanto, foi similar à obtida por SAAVEDRA VELEZ (1986), quando o corte foi efetuado aos 98 dias de idade $(2,62: 1)$, e superior à de 143 dias de idade $(1,58: 1)$. Foi superior, também, à do trabalho de SEIFFERT e THIAGO (1983), em condições de cerrado brasileiro (1,0:1). Para o guandu, o valor de 5,25:1 foi bastante superior à proporção obtida, no cerrado, por SEIFFERT e THIAGO (1983), de 0,8:1. O mesmo ocorreu com a soja, cuja relação foi de 1,63:1, enquanto a de PEIXOTO et al. (1965) foi de 0,72:1.

Já a relação de 1,22:1 do rami foi um pouco inferior à citada por ANDRIGUETTO (1966) para o resíduo constituído de folhas, ponteiros e caules fragmentados, de $57,5 \%: 42,5 \%$, ou seja, 1,35:1, quando considerada 
Tabela 1 - Proporção (\%) e relação folhas:hastes das forrageiras Table 1 - Forage leaves:stems proportion (\%) and ratio

\begin{tabular}{|c|c|c|c|c|}
\hline $\begin{array}{l}\text { Forrageira } \\
\text { Forage }\end{array}$ & $\begin{array}{c}\text { Porção } \\
\text { utilizada } \\
\text { Used portion }\end{array}$ & $\begin{array}{c}\text { Folhas } \\
(\%) \\
\text { Leaves }(\%)\end{array}$ & $\begin{array}{c}\text { Hastes } \\
(\%) \\
\text { Stems }(\%)\end{array}$ & $\begin{array}{c}\text { Relação } \\
\text { folhas:hastes } \\
\text { Leaves:stems ratio }\end{array}$ \\
\hline Leucena & Folíolos & 73 & 27 & $2,70: 1$ \\
\hline Leucaena & Leaflets & & & \\
\hline Guandu & Folíolos & 84 & 16 & $5,25: 1$ \\
\hline Pigeon pea & Leaflets & & & \\
\hline Soja perene & Folíolos & 62 & 38 & $1,63: 1$ \\
\hline Glycine & Leaflets & & & \\
\hline Rami & Folhas & 55 & 45 & $1,22: 1$ \\
\hline Ramie & Leaves & & & \\
\hline Folhas de mandioca & Folhas & 80 & 20 & $4,00: 1$ \\
\hline Cassava leaves & Leaves & & & \\
\hline
\end{tabular}

em relação ao peso.

A proporção folhas:hastes para a mandioca foi de 4,0:1; no entanto, a literatura consultada não fornece dados que permitam comparação com este dado. DESCHAMPS e VETTERLE (1995), avaliando a parte aérea da mandioca, concluíram que somente as folhas jovens apresentam potencial para serem utilizadas na alimentação de ruminantes, sem possíveis comprometimentos no desempenho animal.

Em todos os casos, as diferenças na relação são atribuídas às partes das plantas utilizadas na avaliação. Neste trabalho, apenas as hastes mais finas foram computadas, ao passo que a maioria dos trabalhos consultados incluiu, também, porções mais lenhosas. Outros fatores podem ter influenciado a relação, como o estádio de desenvolvimento da planta, a cultivar e, provavelmente, o tipo de solo no qual a planta se encontrava.

Os teores de matéria seca (MS), proteína bruta (PB), fibra em detergente neutro (FDN), fibra em detergente ácido (FDA), nitrogênio insolúvel em detergente ácido (NIDA), extrato etéreo (EE), cinzas e carboidratos não-estruturais (CNE) das forrageiras estudadas constam da Tabela 2.

Os limites para os teores de FDN e FDA registrados na literatura para as folhas de leucena variam de 17,7 a $50,2 \%$ e de 11,9 a $29,08 \%$, respectivamente; para FDN, os limites inferiores foram verificados por YADAV e YADAV (1988) e os superiores, por CHAKRABORTI et al. (1988) e, para FDA, por CHAKRABORTY e GHOSH (1988), sendo intermediários às porcentagens observadas neste trabalho, 37,06 e 13,43\% para FDN e FDA, respectivamente. No entanto, o valor de FDN foi superior ao observado para o feno de leucena colhido nos meses de março/abril e setembro/outubro, em
Sobral/CE, por VASCONCELOS et al. (1997a), 27,4 e 22,3, respectivamente, enquanto a FDA apresentou valor bem próximo aos obtidos pelos autores, 14,6 e 12,7, nos dois períodos do ano.

O guandu foi, entre as forrageiras estudadas, a que apresentou os maiores teores de FDN $(58,22 \%)$ e FDA $(41,96 \%)$. Já os folíolos de soja perene apresentaram conteúdos de FDN $(50,06 \%)$ e FDA $(28,84 \%)$ inferiores aos observados no feno de soja, 63,17 e $45,17 \%$ (CAIELLI et al., 1979) e 63,30 e 47,15\% (SINGH e NARANG, 1991), para FDN e FDA, respectivamente, e $59,4 \%$ de FDN (FRANZOLIN et al., 1995).

As folhas de rami exibiram a mais baixa porcentagem de fibra (26,18\% FDN e 14,52\% FDA), exceto pela leucena, que teve teor de FDA 1,09 pontos percentuais abaixo.

Os conteúdos de FDN e FDA das folhas de mandioca foram 43,74 e $30,04 \%$, respectivamente, sendo o de FDA mais de três vezes superior aos $8,5 \%$ obtidos por RAVINDRAN (1993) para a farinha de folhas.

Os valores percentuais médios e os desviospadrão, para o desaparecimento de FDN e FDA, observados no tempo zero $\left(\mathrm{t}_{0}\right.$, correspondente à fração solúvel e às partículas eliminadas através da malha dos sacos de náilon quando lavados em água), em função dos horários de incubação no rúmen para leucena, guandu, soja perene, rami e folhas de mandioca, constam da Tabela 3.

Para a FDN dos folíolos de leucena, só após 18 horas porção significativa ( $45 \%)$ do material havia sido degradada, ao passo que, com 12 horas, menos de $20 \%$ do total potencialmente degradável havia desaparecido (Tabela 3).

Na Tabela 4, estão apresentados os parâmetros de degradação ruminal da FDN e FDA de todas as 
Rev. bras. zootec.

Tabela 2 - Teores de matéria seca (MS), proteína bruta (PB), fibra em detergente neutro (FDN), fibra em detergente ácido (FDA), nitrogênio insolúvel em detergente ácido (NIDA*, \% do N total; e NIDA, \% da PB), extrato etéreo (EE) e carboidratos não estruturais (CNE) (\% na MS) das forrageiras usadas para incubação ruminal

Table 2 - Forages dry matter (DM), crude protein (CP), neutral detergent fiber (NDF), acid detergent fiber (ADF), acid detergent insoluble nitrogen ( $A D I N^{*}, \%$ of total $N$; and $A D I N, \%$ of $C P$ ), ether extract $(E E)$ and no structural carbohydrates (NSC) (\% of DM) values used for ruminal incubation

\begin{tabular}{|c|c|c|c|c|c|}
\hline $\begin{array}{l}\text { Componentes } \\
\text { Components }\end{array}$ & $\begin{array}{l}\text { Leucena } \\
\text { Leucaena }\end{array}$ & $\begin{array}{c}\text { Guandu } \\
\text { Pigeon pea }\end{array}$ & $\begin{array}{c}\text { Soja perene } \\
\text { Glycine }\end{array}$ & $\begin{array}{l}\text { Rami } \\
\text { Ramie }\end{array}$ & $\begin{array}{c}\text { Folhas de mandioca } \\
\text { Cassava leaves }\end{array}$ \\
\hline MS & 87,95 & 90,31 & 86,59 & 88,90 & 89,13 \\
\hline $\begin{array}{l}D M \\
\mathrm{~PB} \\
C P\end{array}$ & 25,45 & 19,98 & 26,01 & 27,58 & 37,63 \\
\hline $\begin{array}{l}\text { FDN } \\
N D F\end{array}$ & 37,06 & 58,22 & 50,06 & 26,18 & 43,74 \\
\hline $\begin{array}{l}\text { FDA } \\
A D F\end{array}$ & 13,43 & 41,96 & 28,84 & 14,52 & 30,04 \\
\hline $\begin{array}{l}\text { NIDA* } \\
A D I N^{*}\end{array}$ & 7,59 & 26,25 & 6,38 & 2,83 & 9,58 \\
\hline $\begin{array}{l}\text { NIDA } \\
A D I N\end{array}$ & 1,93 & 5,24 & 1,66 & 0,78 & 3,60 \\
\hline $\begin{array}{l}\mathrm{EE} \\
E E\end{array}$ & 5,41 & 6,90 & 5,08 & 9,70 & 5,86 \\
\hline $\begin{array}{l}\text { Cinzas } \\
\text { Ash }\end{array}$ & 9,82 & 4,38 & 8,64 & 18,02 & 6,86 \\
\hline $\begin{array}{l}\mathrm{CNE} \\
N S C\end{array}$ & 24,19 & 15,76 & 11,87 & 19,30 & 9,51 \\
\hline
\end{tabular}

forrageiras.

Devido ao baixo $A(55,45 \%)$ e ao longo TC $(10,21$ horas) da FDA da leucena, esta fração só apresentou nível mais elevado de degradação após 18 horas de incubação, sendo que, às 48 horas, praticamente toda a FDA potencialmente degradável havia sido degradada.

A leucena apresentou rápida taxa de degradação (c) da FDA, em vista da taxa relativamente lenta da FDN. Contudo, como conseqüência de seu longo TC, a FDA teve baixa degradação às 12 horas. A degradabilidade potencial $(A)$ da FDN $(81 \%)$ foi superior à da FDA $(55,45 \%)$ devido ao seu menor TC, o que sugere alta degradação da hemicelulose.

Devido ao longo TC (cerca de sete horas), houve intervalo de 12 horas antes que a degradação da parede celular dos folíolos de leucena se iniciasse, o que, associado à taxa de degradação relativamente baixa, acarretou baixo valor de DE para esta fração. Já o TC da FDA foi mais extenso (10 horas) e sua degradação ocorreram, de fato, a partir das 18 horas.

Para a FDA do guandu, os dados observados não convergiram com a equação não linear, resultando em uma curva pouco comum para alimentos incubados no rúmen. $\mathrm{O}$ efeito linear foi significativo, utilizando-se a equação de primeiro grau para representar o desaparecimento da FDA. Assim, esta fração da fibra não dispõe de valores para tais parâmetros.
Conforme COSTA (1994), a resposta gráfica observada, ou seja, a função matemática pertinente, depende diretamente do tipo de material a ser analisado, de forma que alguns alimentos podem apresentar resposta retilínea.

Nota-se, também, na Tabela 4, que, apesar de o TC da FDN do guandu permitir que sua degradação comece já às seis horas de incubação ruminal, esta só se deu 12 horas após a inserção do material no rúmen (Tabela 3).

O alto conteúdo de NIDA (26,25\%, Tabela 2) pode ter sido responsável pela baixa degradabilidade do guandu, por meio da incorporação do $\mathrm{N}$ e da hemicelulose à fibra indigestível, tendo reduzido, inclusive, a degradabilidade da fibra (VAN SOEST, 1994). A baixa degradabilidade da FDN foi conseqüência, também, de sua baixa taxa de degradação $(2,5 \% / \mathrm{h}$, Tabela 4$)$, que também foi responsável pela baixa DE demonstrada.

Como os potenciais de degradação de todas as frações foram atingidos após 48 horas de incubação ruminal (Tabela 3 ), este período de tempo foi suficiente e adequado para a representação correta da degradação dos folíolos de soja perene.

Constata-se, na Tabela 4, que, para as porções degradáveis da FDN e FDA dos folíolos de soja perene, as taxas de degradação foram elevadas $(18,20$ 
876

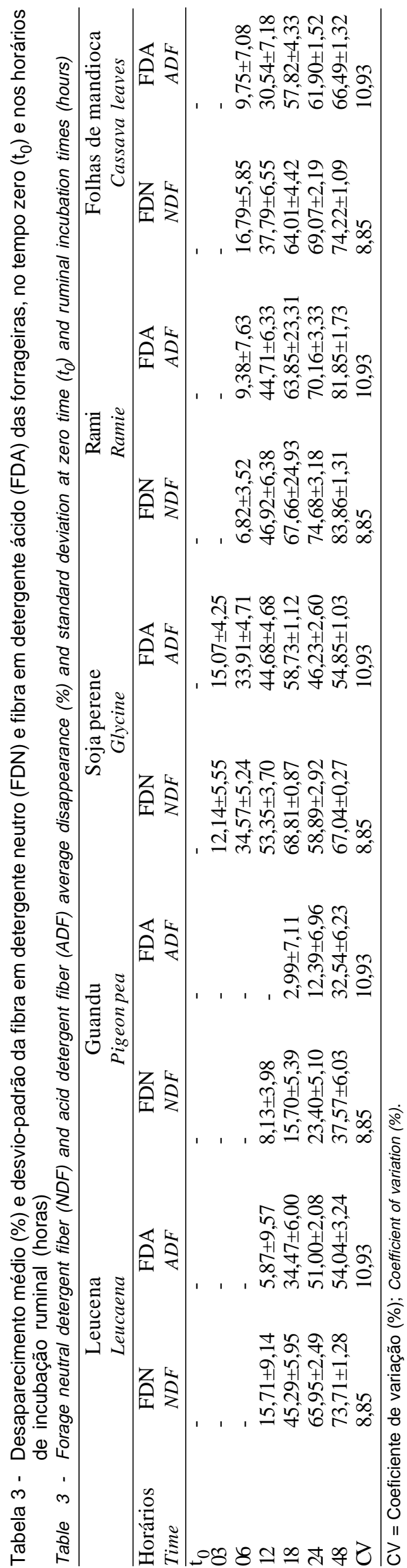

VELOSO et al.

e $21,50 \% / \mathrm{h}$, respectivamente), o que, somado ao baixo teor de NIDA, resultou em degradabilidades potenciais de 65,82 e $53,11 \%$, respectivamente, levando a DE relativamente altas para estas frações. Além disso, os TC da fibra da soja foram curtos, como é normal em leguminosas, comparadas a gramíneas (SHARMA et al., 1988).

A soja foi a forrageira que exibiu as maiores taxas de degradação e o guandu, as menores. Para ambas as frações, os desaparecimentos médios 48 horas após a inserção no rúmen (Tabela 3) praticamente alcançaram os valores das degradabilidades potenciais (Tabela 4), indicando que, para o rami, assim como para a soja, não seria necessária a utilização de um período mais extenso de incubação ruminal.

Como os TC das frações foram curtos, seus desaparecimentos iniciaram-se já a partir de seis horas (Tabela 3 ).

O conteúdo de NIDA do rami foi o mais baixo $(2,83 \%$, Tabela 2$) \mathrm{e}$, associado às altas taxas de degradação, promoveu os maiores desaparecimentos das frações sob estudo e elevadas DE para taxa de passagem de 5\% (Tabela 4).

Os valores para as taxas de degradação foram elevados, levando a altos valores de degradabilidade potencial e DE para ambos os componentes (Tabela 4).

Para a FDN, 50\% de degradação ocorreram 12 horas após a inserção do material no rúmen, devido ao seu TC (3,45 horas). Às seis horas, desapareceram $22 \%$ da FDN potencialmente digestível, que exibiu valor relativamente alto $(77,62 \%)$.

Os desaparecimentos médios das frações após 48 horas de fermentação ruminal (Tabela 3 ) foram bastante próximos de seus respectivos potenciais de degradação, devido às altas taxas de fermentação (Tabela 4).

Para fins comparativos, alguns parâmetros que descrevem a degradação ruminal da parede celular (FDN) das espécies forrageiras estudadas estão contidos na Tabela 5. O rami e a leucena apresentaram os maiores potenciais de degradação da FDN, seguidos pelas folhas de mandioca e pela soja. O guandu exibiu a menor degradabilidade potencial estimada para a FDN.

O TC para FDN variou de duas a sete horas, sendo o mais rápido para a soja e o mais demorado para a leucena.

O potencial de degradação da FDN dos folíolos de leucena foi elevado (81\%) e superior ao verificado por VASCONCELOS et al. (1997b), em cabras mestiças alimentadas com uma dieta composta por 
Rev. bras. zootec.

Tabela 4 - Potencial de degradação $(A)$, fração degradável, obtida pela equação $P=A$ - Be-ct $(B)$, taxa de degradação (c), tempo de colonização (TC), fração solúvel, que corresponde à porcentagem de desaparecimento no tempo zero (S), fração degradável, obtida por $A-S\left(B_{1}\right)$ e degradabilidade efetiva (DE) da fibra em detergente neutro (FDN) e da fibra em detergente ácido (FDA) das forrageiras

Table 4 - Forages neutral detergent fiber (NDF) and acid detergent fiber (ADF) degradation potencial (A), degradable fraction, obtained from the equation $P=A-B e^{-c t}(B)$, degradation rate $(c)$, colonization time $(C T)$, soluble fraction, which corresponds to zero time disappearance percentage $(S)$, degradable fraction, obtained from $A-S\left(B_{1}\right)$ and effective degradability (ED)

\begin{tabular}{|c|c|c|c|c|c|c|c|c|c|c|}
\hline \multirow[t]{2}{*}{$\begin{array}{l}\text { Parâmetros } \\
\text { Parameters }\end{array}$} & \multicolumn{2}{|c|}{$\begin{array}{l}\text { Leucena } \\
\text { Leucaena }\end{array}$} & \multicolumn{2}{|c|}{$\begin{array}{c}\text { Guandu } \\
\text { Pigeon pea }\end{array}$} & \multicolumn{2}{|c|}{$\begin{array}{c}\text { Soja perene } \\
\text { Glycine }\end{array}$} & \multicolumn{2}{|c|}{$\begin{array}{l}\text { Rami } \\
\text { Ramie }\end{array}$} & \multicolumn{2}{|c|}{$\begin{array}{c}\text { Folhas de mandioca } \\
\text { Cassava leaves }\end{array}$} \\
\hline & FDN & FDA & FDN & FDA & FDN & FDA & FDN & FDA & FDN & FDA \\
\hline & $N D F$ & $A D F$ & $N D F$ & $A D F$ & $N D F$ & $A D F$ & $N D F$ & $A D F$ & $N D F$ & $A D F$ \\
\hline $\mathrm{A}(\%)$ & 81,00 & 55,45 & 57,76 & - & 65,82 & 53,11 & 86,72 & 85,48 & 77,62 & 69,44 \\
\hline $\mathrm{B}(\%)$ & 133,00 & 238,83 & 64,80 & - & 93,02 & 72,24 & 133,23 & 111,70 & 108,45 & 107,66 \\
\hline $\mathrm{c}(\% / \mathrm{h})$ & 7,20 & 14,30 & 2,50 & - & 18,20 & 21,50 & 9,90 & 8,20 & 9,70 & 10,20 \\
\hline $\mathrm{TC}(\mathrm{h})$ & 6,89 & 10,21 & 4,60 & - & 1,84 & 1,43 & 4,34 & 3,26 & 3,45 & 4,30 \\
\hline$C T(h)$ & & & & & & & & & & \\
\hline $\mathrm{S}(\%)$ & 0,00 & 0,00 & 0,00 & - & 0,00 & 0,00 & 0,00 & 0,00 & 0,00 & 0,00 \\
\hline $\mathrm{B}_{1}(\%)$ & 81,00 & 55,45 & 57,76 & - & 65,82 & 53,11 & 86,72 & 85,48 & 77,62 & 69,44 \\
\hline $\mathrm{DE}(\%) \mathrm{k}=0,05$ & 47,80 & 41,09 & 19,25 & - & 51,63 & 43,09 & 57,62 & 53,10 & 51,22 & 46,60 \\
\hline $\begin{array}{l}E D(\%) k=0,05 \\
\mathrm{R}^{2}(\%)\end{array}$ & 88,25 & 84,11 & 81,14 & - & 92,84 & 85,52 & 95,13 & 93,42 & 93,47 & 89,72 \\
\hline
\end{tabular}

$\mathrm{k}=$ taxa de passagem.

$\mathrm{R}^{2}=$ coeficiente de determinação.

$k=$ passage rate.

$R^{2}=$ coefficient of determination.

Tabela 5 - Degradabilidade potencial (A), taxa de degradação (c), tempo de colonização (TC) e degradabilidade efetiva (DE) da fibra em detergente neutro (FDN) da leucena, do guandu, da soja perene, do rami e das folhas de mandioca

Table 5 - Leucaena, pigeon pea, glycine, ramie and cassava leaves neutral detergent fiber (NDF) potencial degradability $(A)$, degradation rate (c), colonization time (CT) and effective degradability (ED)

\begin{tabular}{lccccc}
\hline $\begin{array}{l}\text { Parâmetros } \\
\text { Parameters }\end{array}$ & $\begin{array}{c}\text { Leucena } \\
\text { Leucaena }\end{array}$ & $\begin{array}{c}\text { Guandu } \\
\text { Pigeon pea }\end{array}$ & $\begin{array}{c}\text { Soja perene } \\
\text { Glycine }\end{array}$ & $\begin{array}{c}\text { Rami } \\
\text { Ramie }\end{array}$ & $\begin{array}{c}\text { Folhas de mandioca } \\
\text { Cassava leaves }\end{array}$ \\
\hline A $(\%)$ & 81,00 & 57,76 & 65,82 & 86,72 & 77,62 \\
c $(\% / h)$ & 7,20 & 2,50 & 18,20 & 9,90 & 9,70 \\
TC $(\mathrm{h})$ & 6,89 & 4,60 & 1,84 & 4,34 & 3,45 \\
CT $(h)$ & & & & & 51,22 \\
DE $(\%)$ & 47,80 & 19,25 & 51,63 & 57,62 & \\
ED $(\%)$ & & & & & \\
\hline
\end{tabular}

$60 \%$ de volumoso e $40 \%$ de concentrado, de $71,6 \%$. Entretanto, apesar de a taxa de degradação observada neste trabalho ter sido relativamente alta, a DE foi baixa (47,8\%). TEIXEIRA et al. (1997) encontraram valor mais alto de DE da FDN da leucena, 62,9\% (não especificadas a parte da planta e a taxa de passagem que foram utilizadas), usando sacos de náilon com 52 $\mu$ de porosidade para incubação no rúmen de vacas Jersey e Holandesas.

Em conseqüência da baixa taxa de degradação, além do alto teor de NIDA $(26,25 \%$, Tabela 2$)$ verificado para os folíolos de guandu, a degradabilidade potencial e a DE de sua parede celular foram as mais baixas.
A alta taxa de degradação e o curto TC dos folíolos de soja perene não provocaram efeito positivo sobre a degradibilidade potencial, que não foi muito elevada; no entanto, a DE desta forrageira foi alta.

Forragens cujas paredes celulares são degradadas rapidamente, como a soja (TC de 1,84 horas), podem promover maiores taxas de digestão ruminal $(c=18,20 \% / \mathrm{h})$ e de passagem e permitir que o animal consuma mais alimento (MERTENS e ELY, 1982).

As folhas de rami exibiram os maiores potencial de degradação e DE, em virtude de sua alta taxa de fermentação e seu baixo teor de NIDA (2,83\%, o mais baixo).

A degradabilidade potencial, a taxa de degrada- 
ção e a DE da parede celular das folhas de mandioca mostraram valores intermediários aos das demais forrageiras, sendo relativamente elevados.

A DE da parede celular não atingiu $60 \%$ para nenhuma das forrageiras avaliadas e os valores para este parâmetro foram negativamente correlacionados aos conteúdos de NIDA das forragens $(r=-0,986)$.

\section{Conclusões}

Os valores encontrados para o $\mathrm{pH}$ e a concentração de nitrogênio amoniacal do líquido ruminal foram condizentes com adequada fermentação microbiana.

Das forrageiras estudadas, as que apresentaram a maior proporção de folhas em relação às hastes foram o guandu, seguido pelas folhas de mandioca. A relação folhas:hastes das demais foi bem inferior.

As degradabilidades efetivas da fibra em detergente neutro das forrageiras avaliadas foram em torno de $50 \%$, apresentando valores negativamente correlacionados aos conteúdos de NIDA das forragens.

Os elevados potenciais de degradação apresentados indicam que estes alimentos são alternativas que oferecem rápida e abundante disponibilidade de nutrientes para o sistema ruminal.

Por ser um material mais fibroso e com menor conteúdo protéico, o guandu exibiu as mais baixas porcentagens de degradabilidade efetiva, constituindo-se na pior forrageira em termos de aproveitamento dos componentes estruturais.

\section{Referências Bibliográficas}

AGRICULTURAL RESEARCH COUNCIL - ARC, 1984. The nutrient requirements of ruminant livestock, Suppl. 1. Farnham Royal: CAB. 45p.

ANDRIGUETTO, J.M., 1966. Possibilidade do aproveitamento econômico do resíduo de rami no Paraná. Arq. Biol. Tecnol.,12(s.n.):81-113.

ASSOCIATION OF OFFICIAL ANALYTICAL CHEMISTS AOAC. 1980. Official methods of analysis. 13 ed. Washington, D.C. $1015 \mathrm{p}$.

CAIELLI, E.L., WERNER, J.C., BONILHA NETO, L.M., 1979. Valor nutritivo de fenos de nove leguminosas tropicais e do capim gordura (Melinis minutiflora Pal de Beauv.). Bol. Ind. Anim., 36(2):229-245.

CHAKRABORTY, T., GHOSH, T.K., 1988. Chemical composition and nutritive value of subabul (Leucaena leucocephala) foliage in black bengal goats. Ind. J. Anim. Nutr., 5(3):237-239.

CHAKRABORTI, N., MANDAL, L., BANERJEE, G.C., 1988. Chemical composition of some commom tree leaves. Ind. Vet. $J ., 65(2): 145-149$.

COOMER, J.C., AMOS, H.E., WILLIANS, C.C. et al. 1993. Response of early lactation cows to fat supplementation in diets with different nonstrutural carbohydrate concentrations. J. Dairy Sci., 76:3747-3754.

COSTA, A.L.P.R. Caracterização, uso e restrições da curva de degradação da matéria seca em ensaios in situ com ruminantes. Belo Horizonte, MG: UFMG, 1994. 5p. (Seminário apresentado ao Departamento de Zootecnia) - Escola de Veterinária/Universidade Federal de Minas Gerais, 1994.

DESCHAMPS, F.C., VETTERLE, C.P. Avaliação nutricional da parte aérea da mandioca como alimento para bovinos. In: REUNIÃO ANUAL DA SOCIEDADE BRASILEIRA DE ZOOTECNIA, 32, 1995, Brasília, DF. Anais... Brasília: SBZ, 1995. p.217-218.

FRANZOLIN, R., HERLING, V.R., NOGUEIRA FILHO, J.C.M. 1995. Degradabilidade in situ de gramíneas e leguminosas em búfalos sob pastejo. R. Soc. Bras. Zootec., 24(1):8-19.

JONES, R.J., LEFEUVRE, R.P., PLAYNE, M.J. 1992. Losses of dry matter, nitrogen, minerals and fibre fractions from nylon bags containing Leucaena leucocephala and two Calliandra species in the rumen. Anim. Feed Sci. Technol., 37(3/4):297-307.

McDONALD, I. 1981. A revised model for the estimation of protein degradability in the rumen. J. Agric. Sci., 96(1):251252.

MEHREZ, A.Z., ØRSKOV, E.R. 1977. A study of the artificial fibre bag technique for determining the digestibility of feeds in the rumen. J. Agric. Sci., 88(3):645-650.

MERTENS, D.R., ELY, L.O. 1982. Relationship of rate and extent of digestion to forage utilization - a dynamic model evaluation. J. Anim. Sci., 54(4):897-905.

ØRSKOV, E.R. 1994. Recent advances in understanding of microbial transformation in ruminants. Lvstck. Prod. Sci., 39(1):53-60.

ØRSKOV, E.R., McDONALD, J., 1979. The estimation of protein degradability in the rumen from incubation measurements weighted according to rate of passage. J. Agric. Sci., 92(2):499-503.

PEIXOTO, A.M., MORAES, C.L., PRÓSPERO, A.O. Contribuição ao estudo da composição química e digestibilidade do feno de soja perene (Glycine javanica). In: CONGRESSO INTERNACIONAL DE PASTAGENS, 9, 1965, Porto Alegre. Anais... Porto Alegre: s.e., 1965. p.791-795.

RAVINDRAN, V. 1993. Cassava leaves as animal feed: potential and limitations. J. Sci. Food. Agric., 61(2):141-150. In: Nutr. Abstr. Rev., Ser. B, 63(7) (Abstr. 3242).

ROBERTSON, J.B., VAN SOEST, P.J. 1981. The detergent system of analysis and its application to human foods. In: JAMES, W.P.T., THEANDER, O. (Eds.). The analysis of dietary fiber in food. New York: Marcel Dekker. p.123-158.

SAAVEDRA VELEZ, C.E. Rendimento, valor nutritivo $e$ toxicidade de fenos de leucena em ovinos. Belo Horizonte, MG: UFMG, 1986. 77p. Dissertação (Mestrado em Zootecnia) - Escola de Veterinária/Universidade Federal de Minas Gerais, 1986.

SAMPAIO, I.B.M. Experimental designs and modelling techniques in the study of roughage degradation in the rumen and growth of ruminants. Reading: University of Reading, 1988. 228p. Thesis (PhD) - University of Reading, 1988.

SATTER, L.D., SLYTER, L.L. 1974. Effect of ammonia concentration on rumen microbial protein production in vitro. Brit. J. Nutr., 32(7):199-205.

SEIFFERT, N.F., THIAGO, L.R.L.S. 1983. Legumineira - cultura forrageira para produção de proteína. Campo Grande: EMBRAPA/CNPGC. 52p. (Circular Técnica, 13).

SHARMA, B.K., ERDMAN, R.A., REEVES, J.B. 1988. Rate 
Rev. bras. zootec.

and extent of in situ digestion of medium and high quality alfafa and orchardgrass neutral detergent fiber as determined by extended periods of incubation time. J. Dairy Sci., 71(12):3509-3513.

SINGH, B., NARANG, M.P. 1991. Rumen available carbohydrate content of various forages. Ind. J. Anim. Nutr., 8(2):93-96.

TEIXEIRA, J.C., EVANGELISTA, A.R., ALQUERES, M.M. et al. Porosidade dos sacos de náilon na determinação da degradabilidade ruminal, através da técnica "in situ": alimentos volumosos. In: REUNIÃO ANUAL DA SOCIEDADE BRASILEIRA DE ZOOTECNIA, 34, 1997, Juiz de Fora, Anais... Juiz de Fora: SBZ, 1997. p.28-30.

VAN SOEST, P.J., 1994. Nutritional ecology of the ruminant. 2.ed. Ithaca: Cornell University Press. 476p.

VASCONCELOS, V.R., RESENDE, K.T., PIMENTEL, J.C.M. et al. Caracterização química de forrageiras do semi-árido brasileiro e suas correlações com alguns parâmetros de degradação. In: REUNIÃO ANUAL DA SOCIEDADE BRASILEIRA DE ZOOTECNIA, 34, 1997, Juiz de Fora. Anais... Juiz de Fora: SBZ, 1997a. p.58-60.
VASCONCELOS, V.R., RESENDE, K.T., PIMENTEL, J.C.M et al. Degradação potencial e efetiva de forrageiras do semiárido brasileiro em caprinos. In: REUNIÃO ANUAL DA SOCIEDADE BRASILEIRA DE ZOOTECNIA, 34, 1997, Juiz de Fora. Anais... Juiz de Fora: SBZ, 1997b. p.49-51.

YADAV, P.S., YADAV, I.S., 1988. Cell wall constituents and mineral contents in subabul (Leucaena leucocephala). Ind. J. Anim. Nutr., 5(3):230-236.

Recebido em: 08/02/99

Aceito em: 21/10/99 